\title{
Mapping the Social Movement Pattern During COVID-19 Outbreaks with the Twitter Metadata by Using Social Network Analysis (SNA) Method
}

\author{
Mohammad Thoriq Bahri ${ }^{1} *$, Yusuf Hakim ${ }^{1}$, Rezza Fauzy Sucipto ${ }^{1}$ \\ ${ }^{1}$ Directorate General of Immigration, Ministry of Law and Human Rights of the Republic of Indonesia Jakarta, \\ Indonesia \\ *Corresponding author. Email: $\underline{\text { muhammad.thoriq.bahri@gmail.com }}$
}

\begin{abstract}
The National positivity rates reached 14,1 percent in September 2020. More than 4000 cases were confirmed in a day, pushing the government to implement a strict policy that potentially creates pros and cons and may trigger social movement in the affected society. In the theoretical framework, the social movement started in four main stages: emergence, coalescence, bureaucratization, and decline. The polarization of the movement is usually started by the grassroots actors towards a common interest. This research aimed to analyze the social movement's pattern and characteristics in the digital sphere by using the Social Network Analysis (SNA) method. It particularly seeks to understand the conversation network and involved actors by analyzing the Twitter dataset containing 36,929 tweets, with "COVID19Indonesia," "Inpres" and "Pemerintah" words, obtained from July to September 2020. The RStudio Tools used to conduct sentiment analysis to gather people's responses to the COVID-19 related policy, and Gephi Mapping Software to identify the conversation pattern between related actors. The research findings are that government-related accounts can be identified as a conversation starter. A key-person like @ Fadlizon can be identified as an influencer. The mainstream media can be identified as active engagement, while ordinary people can be identified as the network builder. The conversation networks, which the government and mainstream media led, successfully triggered a social movement to support a positive public opinion about the Government Policy to Fight COVID-19 Pandemic. The sentiment analysis concluded that 65 percent responded positively, 18 percent neutral, and only 10 percent responded negatively to the government policy during the COVID-19 pandemic. The findings show the opposite aspects compared to the social movement theory. Firstly, the key actors and movement polar are dominated by the government-related and mainstream mass media to support the government policy itself, not from the grassroots actors. Secondly, Involved actors are borderless, who came from many different backgrounds and separate into a smaller conversation network to support common goals. However, the main social movement pattern is still relevant to the main stage. It started with emergence, coalescence, bureaucratization and ended with a decline stage. The new phenomenon discovered is that the digital social movement is coming from the people against the government policy or the government to influence public opinion.
\end{abstract}

Keywords: covid-19, social movement, social network analysis (SNA), immigration, digital sphere, social media, twitter.

\section{INTRODUCTION}

COVID-19 pandemic is becoming a serious problem in Indonesia. At the beginning of September 2020, the average number of national COVID-19 confirmed cases had reached 4000 in a day and keep increasing to 6267 daily confirmed cases, with a positivity rate of 14,1 percent as of November 29, 2020 [1]. The trends show if the number of infections is increasing every day, then dynamic policies are needed to be taken by the government because the situations can change very quickly.

The rapid change of the situation made the government implemented a strict regulation to increase the people's awareness and discipline to minimize the spread of COVID-19. The Presidential Order Number 6 of 2020 about Increased Discipline and Law Enforcement of Health Protocols in the 
Prevention and Control of Corona Virus Disease of 2019 [2] is one of the government efforts focusing on law enforcement. Law enforcement is needed because according to the evaluation of the task force team, the number of COVID-19 confirmed cases in several provinces, especially in the Jawa Tengah and DKI Jakarta Provinces, had been identified to reach more than 1000 cases per day per November 29, 2020 , or about 25 percent of the total COVID-19 daily cases nationwide [3]. The high number of deaths making hospitals and cemeteries prepared for COVID-19 victims are almost full.

After the implementation of the regulations, the number of violators of health protocol increased significantly. The total amount of fine collected in Jakarta reached about 4,9 billion Rupiahs by November 25, 2020 [4]. The same trends also happen in many provinces in Indonesia. There are many pros and cons about the implementation of the strict regulation nationally. The discussion about these issues mostly happened on social media, especially on the Twitter platform, as one of Indonesia's most popular social media platforms with more than 22,8 million users.

The social media platform transformed the social structure and interaction of the society, known as "Information Society" [5]. The information society is categorized as the networked citizen, which connected each other and moves all of the social life to the internet, including the way people protest or the way the people speak up to the government decision or policy, which organized by the common goal[6].

The social movement can be defined as an organized movement involving informal social entities that engage in extra-institutional conflict towards a common goal [7]. As described before, the common goal between the involving entities becomes the most important aspect of how the digital social movement can be triggered in an information society.

As a social media platform, Twitter provides real-time updates about what happened in the world better than any other social network platform to spread information across different conversation networks, resulting in public engagement [8]. Twitter is conceptualized as the big data producing platform. Data generated by the Twitter platform can help the researcher understand the fact by zooming in interest, filtering out the data, selecting an item, understanding relationships between the items, extracting the details of the data, including how the people respond to the government policy.
It is difficult to understand the interactions and the digital social movement potential on the Twitter platform because one of the digital social movements' unique characteristics is big data analysis [9]. Big data analysis changes how social research is conducted, without a survey, without a margin of error, and the results can be borderless from any segment of society.

Social Network Analysis (SNA) was developed as the new method for analyzing the big data in the social media platform, including the Twitter platform. SNA analysis can be used to understand thousands of tweets that used the COVID-19 related hashtag. Conversations on the Twitter platform can be analyzed using big data analysis. The SNA analysis is becoming very important to understand the directions of the digital social movement.

The spread of the COVID-19 urged the government to implement strict policy. It will create a variety of responses. The statistics show that more than 628 Million tweets worldwide use the COVID19 related hashtag, and more than 50 Million are tweets by Indonesian users as of September 8, 2020 [10]. That figure indicates that the digital Social movement is known as the most effective way of creating borderless movement, from the grassroots to the elite's communities, spreading across social dimensions, structure, and overlaying existing power relations in movements [11]. These characteristics make the SNA analysis the most effective way to understand the people's responses and the future potential social movement as the results of government policy implementation.

This research aimed to understand the responses and the digital social movements pattern toward the government policy during the COVID-19 outbreaks using 39.393 Twitter datasets from July to September 2020. The public reactions toward the government policy will be extracted, the pattern of the movement will be identified, and the opinion leader will be distinguished. Those data will be analyzed with the Social Movement theory to understand the potential public movement.

\section{RESEARCH METHOD}

The descriptive qualitative method with the Social Network Analysis (SNA) will be used as the research framework. The main reason for choosing the method is because the interactions in Twitter are happened in text-based, and most of them are stored and distributed in the format of big data. The outcome of text analysis using SNA must be analyzed with the theoretical overview to understand 
the society followed by the descriptive qualitative method.

The SNA can be described as a social media network mapping method, which is used to identify patterns, structures, and mapping of existing communication networks on a social media platform, the relationship between one entity unit and other entity units [12].

\subsection{Data}

The dataset used in this research consists of 36,929 tweets worldwide, obtained from July to September 2020. The dataset only includes the tweets which contain the "COVID19Indonesia," "Inpres," and "Pemerintah" words.

\subsection{Tools}

The analysis tools, RStudio software Version. 4.0, with the Snowball, Rstem, TwitteR, TM, NLP, Sentiment Analysis, and Sentiment Packages, was used to analyze the text or tweets and sentiments in those particular tweets. Then, the interaction map and actors identification were analyzed with the Gephi Mapping Software, version 0.9.2. The RStudio programming with the Python Language Programming was used to decipher bigdata-based data taken from Twitter. The big data analysis steps can be explained as follows [13]:

\subsection{Data Mining}

The first stage in decomposing big data is doing the data mining process, or mining data. This is the process of extracting data from data sources and arranging them sequentially for analysis [14]. In this research, the data used to perform the analysis of 39.393 twitter datasets, obtained from July to September 2020, containing the "COVID19Indonesia," "Inpres," and "Pemerintah" words.

\subsection{Data Cleaning}

The second stage is to carry out the data cleaning process, which means removing unnecessary determinants variable in a dataset, with data properties and variables ready to be processed as needed [15]. The data cleaning process is carried out using RStudio, by deleting empty, duplicated, and unreadable content (only in the form of certain characters, without text).

\subsection{Data processing}

The next stage is to do data processing. The findings from decomposing data based on Social Network Analysis (SNA) will then be processed using the Sentiment Analysis method. In Sentiment Analysis, the data processing process is carried out by going through the following procedures [16]: (1) Calculation of the number of sentiments from tweets on the prepared dataset, (2) Labeling sentiments that are adjusted to a database of negative, positive, and neutral words by the lexicon Dictionary, (3) Deleting tweets posted by bots/robots, (4) Cleaning up certain symbols, such as numbers, symbols, and URLs. (5) Extracting adjectives from the lexicon word database, (6) Counting the number of negative, positive, and neutral words based on the lexicon Dictionary, (7) Omitting words other than adjectives.

\subsection{Data presentation}

This is the final stage to present the data in the form of the actor's identifications, visualization of conversation networks, and conducting sentiment analysis. The actor's identifications and visualization were used in the Gephi software, and sentiment analysis to understand the people's responses was conducted with RStudio Software.

Table. 1. Steps for Data Presenting in the Social Network Analysis (SNA)

\begin{tabular}{ll}
\hline \multicolumn{1}{c}{ Task } & \multicolumn{1}{c}{ Description } \\
\hline $\begin{array}{l}\text { Segmentation or } \\
\text { Clustering }\end{array}$ & $\begin{array}{l}\text { Clustering the groups that } \\
\text { describe data }\end{array}$
\end{tabular}

Classification

Add the labels to the datasets

Analyzing the relationship between the Association users, and conversation clusters

Wrapping up the items, to

Deviations understand the information spread

Lines and curves
summarizing the
database, often over time

Trends 
Generalizations and visualize the data
Compact descriptions of the data by using visualization
Source: Kitchin, R. (2014;72)

It is premised on the notion that all massive datasets hold meaningful information that is nonrandom, valid, novel, useful, and ultimately understandable if we analyze the dataset in the right way [17]. Finally, the findings were analyzed with the social movement theory to understand how the social movement is conducted in the digital and connected society.

\section{FINDINGS AND DISCUSSION}

The finding section explains the results of Twitter database extraction. Involved actors and their roles in the conversation networks are identified. The mapping of the conversation pattern between actors is visualized. After the findings are explained, the discussion analyzes the findings in reference to related regulations and social movement theory.

\section{A. Actor Identification}

The analysis focused on the identification and classification of the actors. The SNA Analysis tools' indicators determine conversation Starter, Influencer, Active Engager, Network Builder, and Information Bridge. The actor's classifications table is explained as follows:

Table. 2. SNA Analysis for Actors Classifications

\begin{tabular}{ll}
\hline Classification & \multicolumn{1}{c}{ Description } \\
\hline & $\begin{array}{l}\text { Conversation Starter is } \\
\text { a user in-network with } \\
\text { numerous "in-degree" }\end{array}$ \\
Conversation & $\begin{array}{l}\text { links and a few or none } \\
\text { "out-degree" links. }\end{array}$ \\
& $\begin{array}{l}\text { They start the original } \\
\text { topic. }\end{array}$ \\
& $\begin{array}{l}\text { An influencer is an } \\
\text { opinion leader in the }\end{array}$ \\
network. An influencer \\
influencer \\
plentiful "in-degree" \\
links and few "out- \\
degrees" links. They
\end{tabular}

influence the opinion of other users in the network by creating frequent tweets that are retweeted by other users (their followers).

An active engager in an online discussion network with many

"out-degrees" and a Engager few or none "indegree" links. They

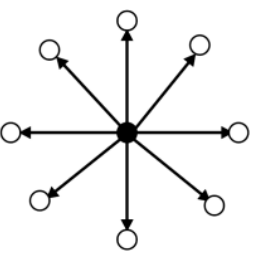
distribute information from the influencers.

Despite having a few "out-degrees" and a few or none "indegree" links in an online discussion Network network, the network Builder builder plays an important role in the network. The main role of the network builder is connecting two or more influencers.

An information bridge is a user in an online discussion network with a few "in-degrees" and "outdegree" links. The information bridge

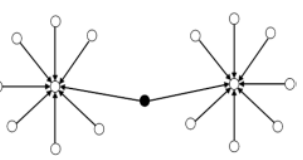
role is to assist influencers and is actively engaged in the network to connect with other users.
Information Bridge
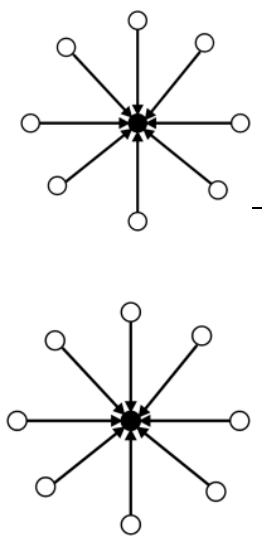
follows:

The analysis begins with understanding the items which contain a summary of the datasets. The details of tweets data used in this research are as

Table.3. Details of the analyzed tweet

\begin{tabular}{lcc}
\hline \multicolumn{1}{c}{ Items } & Number \\
\hline Retweet & 95725 \\
Tweet & 36929
\end{tabular}


Replies to

38173

Source: Data Analysis.

The most active users who have a role in spreading their information will be measured by the number of Influences in a conversation network. Users mentioned in the table below have control over the information passing between other users in the conversation networks.

Table. 4. Most Active Users in the Conversation Network

\begin{tabular}{llr}
\hline \multicolumn{1}{c}{ Account } & \multicolumn{1}{c}{ Affiliation } & Influence \\
\hline @Tribun Pontianak & Media & 174363 \\
@Aw3126 & Ordinary People & 11054 \\
@LintasKebumen & Media & 4611 \\
@dhieKang & Ordinary People & 1771 \\
@ AuliaAkbarShan & Ordinary People & 1407 \\
@TravelNewsAsia & Media & 1119 \\
@Lampostco & Media & 396 \\
@zax2000 & Ordinary People & 394 \\
@iqbalbasagili & Ordinary People & 281 \\
@iklanraja & Company & 259 \\
\hline
\end{tabular}

Source: Data Analysis

Based on the data above, the identification of the key actors involved in the COVID-19 related hashtag in the Twitter platform conversation network can be explained as follows:

\section{1) Conversation Starter}

First, the conversation starter is identified using the statistical analysis of edge weight, which showed the network ranking of the top connected Twitter users. They are indicated with the high value of edge weight, high value on the "in-degree" links, and only a few the "out-degree" links, and the high number of impressions [18]. The posts from these users are tweeted, replied to, and retweeted by most of the accounts that using "COVID19Indonesia," "Inpres," and "Pemerintah" words. The conversation starter can be identified as follows:

Table. 5. The Conversation Starter in the COVID19 Hashtags

\begin{tabular}{lll}
\hline Accounts Name & Background & Impressions \\
\hline @Jokowi_id & Media & 16.700 .000 \\
@DKIJakarta & Government & 3.880 .000 \\
@Kompascom & Media & 3.640 .000 \\
@ Aniesbaswedan & Media & 2.459 .000
\end{tabular}

\begin{abstract}
@Detikcom
Government

Source: Data Analysis

The conversation starter users who identified based on the data analysis are trying to create a conversation cluster and build public concern regarding an issue. The digital social movement can be triggered if a population has the same goals. It will start the emergence steps, the first steps to form a traditional social movement, the conversation starter. Government-related and mainstream media accounts dominate the conversation starters and create a common goal, making the relation between the actors in a conversation cluster blurry and borderless [19].
\end{abstract}

\section{2) The Influencer}

The influencers created opinions for the users in the conversation network by making frequent tweets from the Conversation Cluster, and then the tweets are retweeted by other users. They are identified using the value of Betweenness Centrality, which shows how likely this person is to be the most direct route between two people in the network, who spread the information to another user in more than one conversation cluster. The identified influencer accounts can be shown as follows:

Table. 6. The Influencer Identification Table

\begin{tabular}{|c|c|c|}
\hline User & $\begin{array}{c}\text { Graph } \\
\text { Analysis }\end{array}$ & $\begin{array}{c}\text { Out } \\
\text { Degree }\end{array}$ \\
\hline @Fahrihamzah & & 292 \\
\hline @Tifsembiring & & 467 \\
\hline @Fadlizon & & 309 \\
\hline @Rmol_id & & 160 \\
\hline @Tri_rismaharini & & 159 \\
\hline
\end{tabular}




\section{Source: Data Analysis}

The influencer has dominated by the government and activist-related accounts, which pass the information from the conversation starter. Then, the information will spread between their followers, creating many conversation clusters with different common goals. In the traditional social movement, an influencer is trying to do coalescence, which can be defined if the discussions and some perspectives started to be sounded [20].

\section{3) Active Engagers}

Active Engagers are indicated by the users who have many "out-degrees" and a few or none "indegree" links. Active engagers are responsible for the distribution of the information in their conversation network. Active engager can be shown as follows:

Table. 7. Active Engagers Identification Table

@sername

Source: Data Analysis

The role of active engager in the digital social movement is to build the bureaucratization, known as "formalization" [21] of the movement. Thus, the actors will become organized, and the people's awareness about the issues spread by the active engagement is escalated.

\section{4) Network Builder}

Fourth is the network builder, identified by the users who have a few "out-degrees" and a few or none "in-degree" links. The primary role of the network builder is to connect two or more influencers in the network. The analysis of the top 5 COVID-19 hashtag network builder can be identified as follows:

Table. 8. The Network Builder in the COVID 19

\begin{tabular}{lcc}
\multicolumn{1}{c}{ Hser } & In-Degree & Out Degree \\
\hline @Idntimes & 0 & 0 \\
@Humaspolisi & 0 & 0 \\
@Its_dul & 0 & 0 \\
@Meonkbaong & 0 & 0 \\
@Serambinews & 0 & 0
\end{tabular}

Source: Data Analysis

These users connect conversation clusters in the network. Those users are not creating any tweets in their network of followers, but the role of the network builder users is to retweet the tweets from one of the influencers to another influencer followers, then it will be creating a new conversation cluster. A network builder's role is very important to pass the information between the influencer in a conversation network.

\section{5) Information Bridge}

The last step to understanding the digital social movement pattern is to identify the Information Bridge. An information bridge is a user in an online discussion network with a few "in-degrees" and "outdegree" links. The information bridge role is to assist influencers and actively engaged in the network to connect with other users. 
The analysis results show that no information bridge can be identified. From the social movement perspective, the movement already reached the declined steps, which are the last steps of the social movement. The declined steps can be divided into four ways Repression, Cooptation, Success, and Failure [22]. The declined steps are explained in the discussion steps when the government is starting to adopt the COVID-19 related policy, and the people have the same opinion to reach common goals, conducted using the interaction map by resuming all of the analyzed data above. The graph's vertices in the COVID-19 Network conversation were grouped by cluster using Gephi Visualization Software. The Conversation clusters contain 12460 Nodes and 9363 Edges. Every conversation between users is shown by using an arrow that illustrates the connection between users in conversation. The figures illustrate the social structure of digital interaction of the digital social movement identified

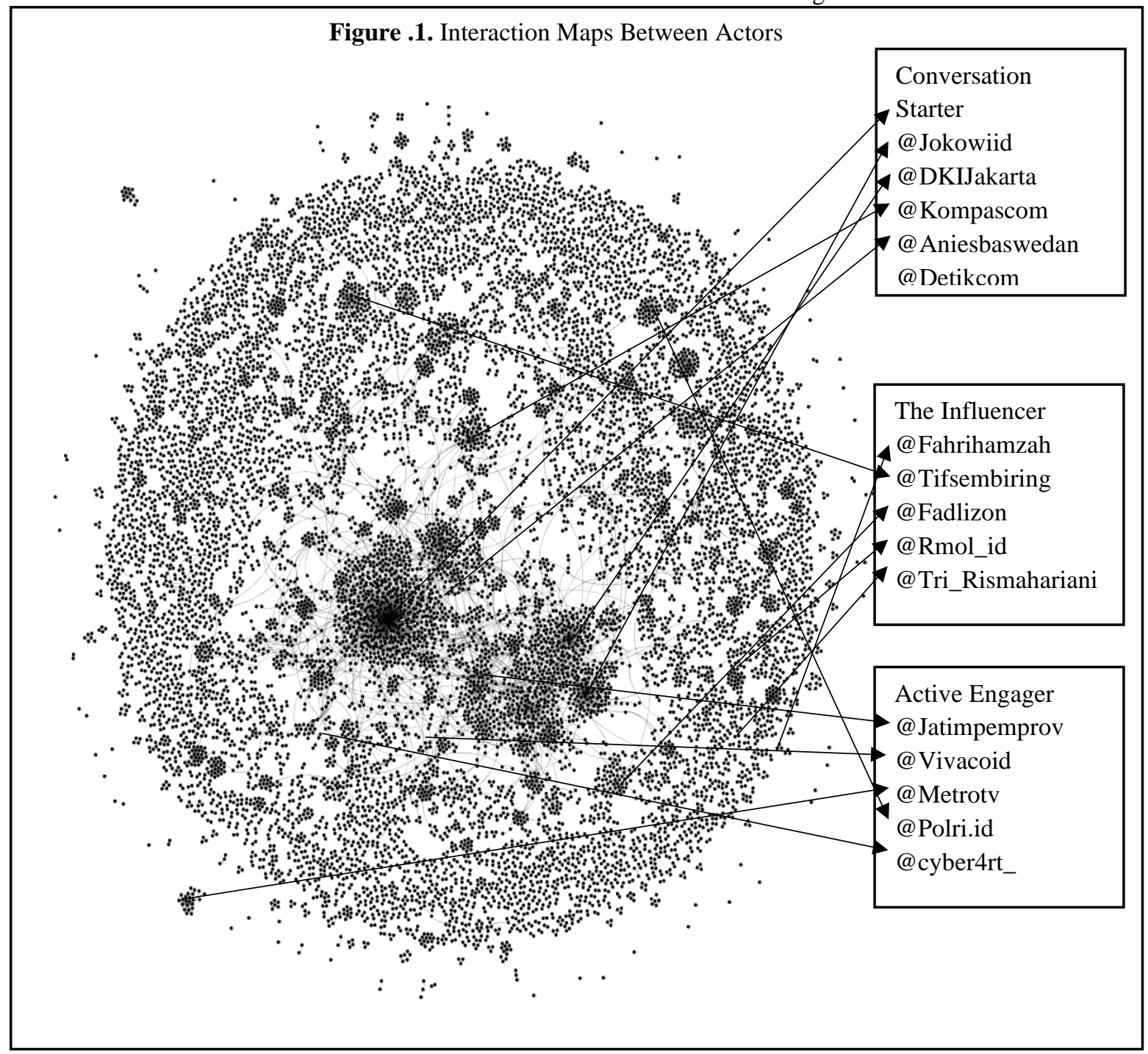

Source: Data Analysis

which is to fight the spread of the COVID-19 pandemic.

\section{B. Interaction Map}

After identifying all of the conversation networks and involved actors on the related parameters in the COVID-19 Conversation network, the structural conversation analysis will be in the Twitter platform, which used the COVID-19 hashtag as shown in Figure 1.

Based on the data visualization above, it can be concluded that the government-related accounts dominated the shaping of people's opinion on response to the common policy. @Jokowi_id as the Indonesian President Official account is still becoming a conversation starter, followed by 
@DKIJakarta as Jakarta Municipal Government Official Account, Kompas.com a Mainstream media account, @Aniesbaswedan, as the official account for DKI Jakarta Governor, and Detik.com as the mainstream media account. The related findings are also found in the influencer, which is dominated by government-related accounts and mainstream media.

Government-related and mainstream media accounts also dominated the active engagers responsible to keep the topic discussed on their networks. Active engagers passed the information from the influencer to their conversation network. For example, the @jatimpemprov accounts retweeted, and discussed with their followers about the issues voiced by @Fadlizon.

The pattern shows that the government organization always becomes the object and subject in a social movement. In conclusion, the figure illustrates and highlights the presence of two key accounts, the government-related users and the mainstream media, which influence the public opinion about the government policy to fight the COVID-19 pandemic.

\section{Public Responses}

The sentiment analysis was conducted to clearly understand the public responses on the Twitter social media platform. Sentiment analysis, also called opinion mining, is a process of understanding, extracting, and processing text data to obtain information and classify the data by using certain parameters. The emoticons analysis was also conducted to understand the people's responses to their emotions.

The datasets were cleaned using the R-Studio Software and translated to English using the Google translation services. The translated tweet text is analyzed with the lexicon word bank, containing more than 5000 positives and negatives English words. Then, the emoticons used by users are classified. After being analyzed, the public responses can be shown as follows:

\section{1) Text Analysis}

The text analysis using the lexicon dictionary in the RStudio software can be shown as follows:
Figure 2. Text Analysis Result

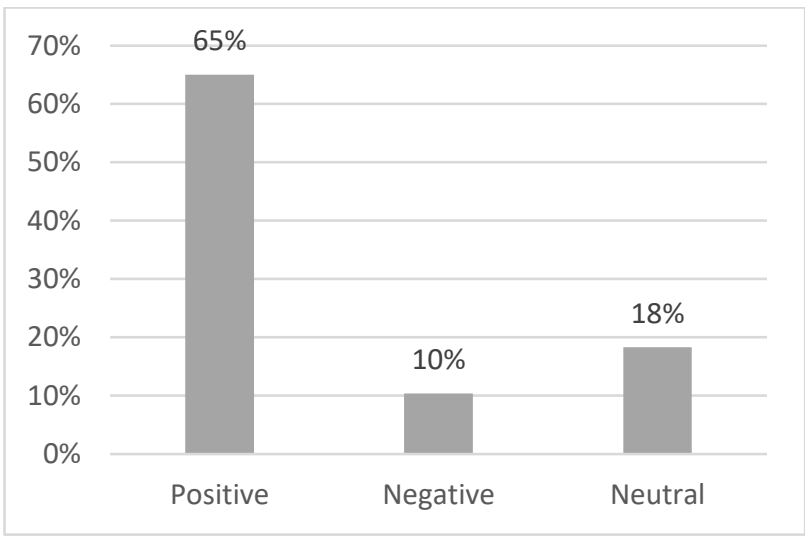

Source: Data Analysis

The results show that 25.626 persons have positive responses, 7210 persons have neutral responses, and only 4093 persons have negative responses. In percentage, 65 users have positive responses, 18 percent neutral, and only 10 percent have negative responses.

\section{2) Emoticons Analysis}

The emoticons analysis using the RStudio Software with the Sentiments Script package is shown as follows:

Table. 9. Emoticons Analysis

\begin{tabular}{ll}
\hline Percentage & \multicolumn{1}{c}{ Emoticons } \\
\hline $1 \%$ & anger \\
$25 \%$ & anticipation \\
$0 \%$ & disgust \\
$8 \%$ & fear \\
$7 \%$ & joy \\
$5 \%$ & sadness \\
$9 \%$ & surprise \\
$10 \%$ & trust \\
$10 \%$ & negative \\
$25 \%$ & positive \\
\hline \multicolumn{2}{|c}{ Source: Data Analysis }
\end{tabular}

The results can be concluded that most people have positive emotions and anticipation. Trust emotions and negative emotions also have the same amount. The fear, sadness, and joy have the same amount as well.

\section{Discussion}

Public policy to reduce the number of COVID19 spread is one of the government initiatives for society's common problem. Presidential Order 
Number. 6/2020 about Increased Discipline and Law Enforcement of Health Protocols in the Prevention and Control of Corona Virus Disease 2019 that enables law enforcement to charge those who violate the health protocol always create pros and cons. The law can be summarized as follows:

Table. 10. Summary of the Presidential Order Number. 6/2020 about Increased Discipline and

Law Enforcement of Health Protocols in the

Prevention and Control of Corona Virus Disease 2019

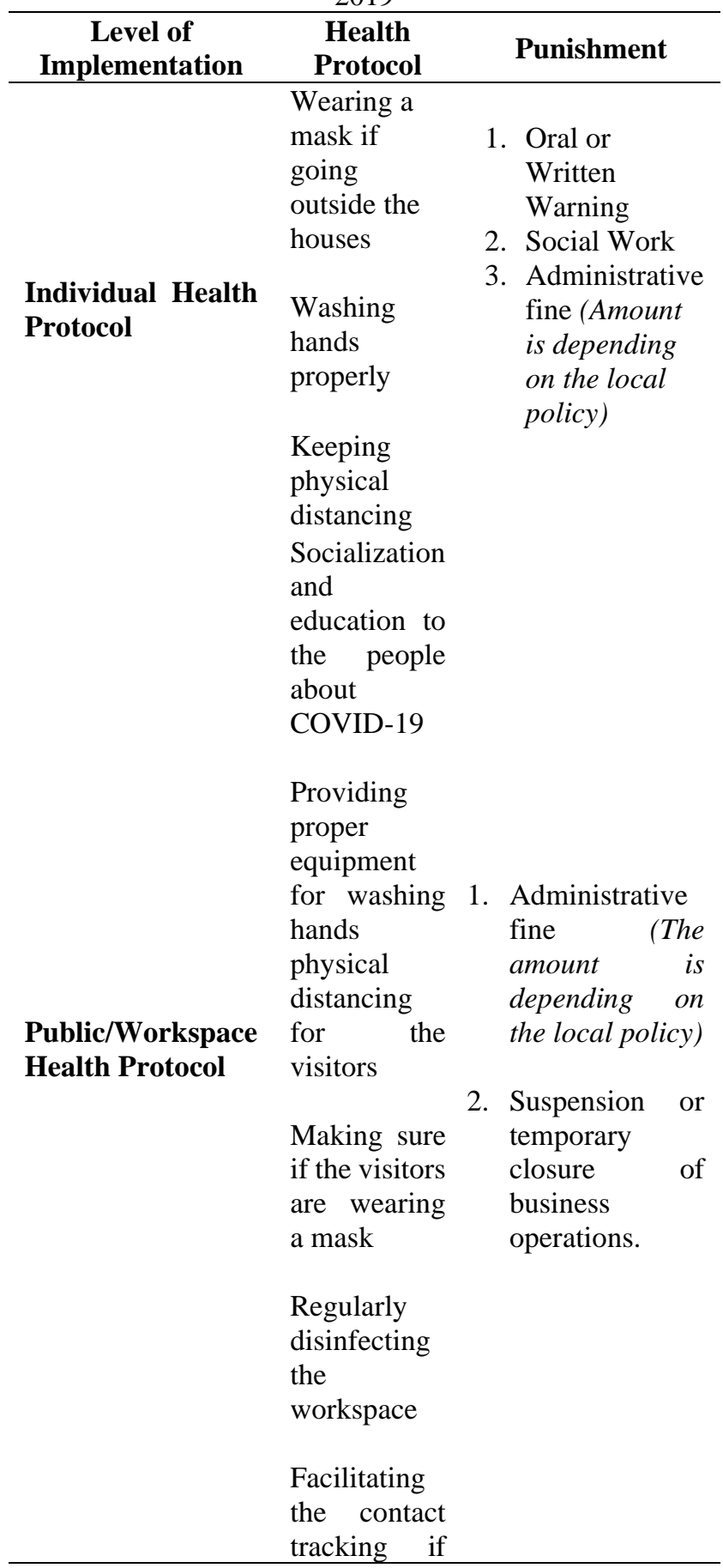

there is a

COVID-19

case

\section{Source: Author Summary}

The implementation of this law creates various responses from society. In this digital era, society expresses its voice via a social media platform. The research found a big pattern changes between the traditional social movement and the digital social movement in the Digital era. The traditional social movement is more concrete, is divided into opposite parties, has the same goal, and mostly happens in a specified social structure against different social class actors. The social movement is created because of the collective dissatisfaction with a certain condition, having enough resources, and having the same identity [23]

On the other hand, digital social movement takes place because of its possibility to lower the individual cost for participation in a social movement, increasing general access to specific information, fostering connectivity between users, and creating a space for users to publish their content. The booming of the social media users creates a new concept inexisted before, the Digital Public Sphere.

The digital public sphere becomes a new public space to discuss issues that happen around social media users. It is characterized by borderless participation and is dominated by multi-actor conversations from various social backgrounds [24].

The public sphere is created by the digital native, which explained as the society, dominated by the young generation who use social media for getting information and discussing a specific issue between them [25]. Based on the data analysis, some of the findings will be discussed as follows.

The first findings explain how Twitter changes the social movement pattern, from the traditional to the digital. Twitter as a social media platform already creates new insight of diffusion because of its ability to spread information and ideas directly, without geographical boundaries. The Twitter users' behavior also breaks the early diffusion theory principles, which believed that to diffuse the ideas rapidly, direct contact between adopters or actors must happen intensively [26]. This is also validated by the research findings that the COVID-19 related hashtag creates a digital social movement to support and spread positive opinion for the government policy to reduce the number of COVID-19 break-ups in a relatively short time. 
The second findings also have a supporting argument about the new public sphere, which happens on Twitter. This is apparent from various social backgrounds who engaged in the conversation, from the Journalist, Private Persons, Celebrity, Media, Activist, Politician, NonGovernment Organization (NGO), International Organization, and Government related accounts. The findings have boldened the characteristic of the digital social movement theories, borderless towards the same goals.

The third findings can be explained as the role of journalists and media. The Journalist and media behavior is just like a private person, using humor and the personal message between the journalist and media users to the private person. The role of media as an information-gathering agent changed as the network development agent. Supporting the argument above, the cross social structural movement makes the burden between mainstream media and ordinary people blurry. On the other hand, the government and celebrity's role is to create a call for action. The information that comes from the journalist and media is retweeted by these clusters and creates many calls for active movement.

Based on the social media mapping, the last findings there was an intense conversation cluster triggered by the influencer, who built the public opinion about the positive impact of the Government Policy against the COVID-19 pandemic. The opinion leaders are the Government related accounts who have the authority to do preventive and repressive actions to fight against COVID-19. There were two dominant users, consist of governmentrelated users and mainstream media users, acting as the "hubs" and "bridges" [27].

In this research, "Hubs" can be explained as the vertices with a high amount of interactions with other vertices. The vertices represent the users in a conversation network, a high in-degree value. When a tweet by conversation starter of influencer has been re-tweeted/commented on by other users many times, the hubs will spread the tweet massively in their network. "Bridges" can be explained as the vertices with a high value of the high betweenness centrality. Bridges users can spread information across the sub-group boundaries and can pass information from one group to another. That successful conversation network in the diffused frames needs both "hubs" and "bridges" to create a massive social movement.

Even though the "bridges" users do not have many connections, they have a significant role in diffusing messages from the conversation starter and influencers. They dramatically increase the conversation clusters to create a social movement against the government-related accounts and International Organization who has authorities to act against COVID-19 Outbreaks.

Interestingly, in this particular case, users' pros and cons are not showing any potential in starting or following the social movement. Based on the social movement theory, the actors will come across various social structures, from the grassroots society to the elites. However, the findings show different channels because the government-related users and mainstream media initiate the opinion creators, leaders, and the social movement to support the government actions against the COVID-19 pandemic. The movement polarity is not against the government, like what happened in particular social movement cases, such as Arab Spring in 2013. The movement polarity is relatively has a goal to make a positive opinion about the government. This means that there is a new phenomenon called the "Government for Government" social movement.

This research has several limitations. First of all, the people who post and interact on the social media platform, Twitter, mostly come from a special group, especially they are interested in talking about COVID-19 on Twitter, which means this research does not represent all of the social structure in the society.

Moreover, the social movement on the internet itself cannot be analyzed by the Twitter social media platform alone. A deep survey must be conducted to understand the COVID-19 social movement phenomenon because the users who use social media to express their argument cannot be considered as the representation of a population. The internet penetration percentage, access to social media, and undocumented movement may occur in society. Thus, it may be biased and difficult to understand the real social movement that happens in a population.

However, this characteristic may be helpful. Suppose the research focused on a particularly active group on a social media platform. In that case, there is the potential to obtain data on groups that do not tend to respond to other research methods. The platforms can host numerous automated 'bots' and professionally managed accounts that pose as genuine human users. Extensive studies should therefore attempt to filter out results from such unconventional sources during analysis. 
This research's potential can be valuable for a deeper and more accurate understanding of how the digital social movement is conducted and to figure out how the new social movement works in further research.

\section{CONCLUSION}

The research findings indicate the digital social movement pattern showed the difference if we compare it to the traditional social movement. The social movement in the digital era is characterized by the borderless movement and cross social structure. It is relatively different from the traditional social movement, mostly divided into opposite parties, has the same goal, and mostly happens in a specified social structure against different social class actors. The social movement is created because of the collective dissatisfaction with a certain condition, having enough resources, and having the same identity.

The pattern shows that the conversation clusters contain all related actors from various backgrounds such as journalists, private persons, celebrities, activists, politicians, social bot, NGOs, international organizations, and companies. They interact borderless with the same goals. Activists, journalists, and ordinary people are identified to become a member of a social movement to support the Government policy to fight COVID-19 pandemic. These findings have boldened the theory of digital social movement

Interestingly, the research findings show the opposite analysis from the theory of digital social movement. The theory said that the movement polar started by the grassroots society, then influenced borderless followers from many social and political backgrounds towards a common interest. However, the findings show that the government-related users and mainstream mass media dominate the key actors and movement polar to supports the government policy itself. However, the main pattern of social movement is still relevant to the main stage. It started with emergence, coalescence, bureaucratization and ended with the decline stage.

The SNA analysis proved quite an effective way to understand the social movement pattern and responses and identified the actors who spread their opinions and the conversation network. Moreover, in the future, rather than using a traditional data gathering method to evaluate the government policy to address an issue, the SNA analysis can be implemented in evaluating government decisions and policy more accurately in a more affordable way.

\section{REFERENCES}

[1] COVID-19 Daily Reports. (2020, November 29. COVID-19 Data Sections. [Online]. Available: https://covid19.go.id/petasebaran.

[2] Hukum Online Law Sections. Presidential Order Number. 6/2020 about Increased Discipline and Law Enforcement of Health Protocols in the Prevention and Control of Corona Virus Disease 2019. [Online]. Available:

https://www.hukumonline.com/pusatdata/d etail/lt5f2b6c91c12f7/node/534/instruksipresiden-nomor-6-tahun-2020.

[3] Pemerintah Daerah Khusus Istimewa (DKI) Jakarta. Sebaran Kasus COVID-19 di Wilayah DKI Jakarta. [Online]. Available: https://corona.jakarta.go.id/id/peta-kasus

[4] J, Arif. (2020, November 25). "Denda Pelanggaran Protokol Kesehatan Mencapai Rp 4,9 Miliar Rupiah". Kompas.com. Available

https://nasional.kompas.com/read/2020/09/ 18/21534411/denda-dari-pelanggarprotokol-kesehatan-terkumpul-hampir-rp$\underline{400 \text {-juta-dalam-4?page }=\text { all }}$

[5] Rayward, W. "Information Revolutions, the Information Society, and the Future of the History of Information Science". Library Trends. Volume 62, pp. 681-713, Oct. 2014, DOI: 10.1353/lib.2014.0001.

[6] Navarria, G. The Networked Citizen. United Kingdom: Macmillan Publishing, 2018.

[7] Diani, Mario. "The Concept of Social Movement". Journal of the Sociological Review. 40. pp. 1 - 25, 2011, DOI: 10.1111/j.1467-954X.1992.tb02943.x.

[8] Appel, G., Grewal, L., Hadi, R. et al. "The future of social media in marketing". J. of the Acad. Mark. Sci. Volume 48, pp. 79-95, 2020, doi:10.1007/s11747-019-00695-1.

[9] Kitchin, R. "The data revolution: Big Data, 
Open Data, Data Infrastructures \& Their Consequences". London, : SAGE Publications, $2014 . \quad$ DOI: $10.4135 / 9781473909472$.

[10] Tweetbinder. "Tweetbinder COVID-19 Hashtag Data". Tweetbinder.com. Available: https://www.tweetbinder.com/.

[11] Christina, F. \& Gillan, K. (2017). Navigating The Technology Media Movements Complex. Journal of Social Movement Studies Volume 164, Pp. 383402 ,

DOI:

10.1080/14742837.2017.1338943.

[8] Siguenza-Guzman, Lorena \& Saquicela, Victor \& Avila-Ordoñez, Elina \& Vandewalle, Joos \& Cattrysse, Dirk. (2015). Literature Review of Data Mining Applications in Academic Libraries. The Journal of Academic Librarianship. 41. 499510. 10.1016/j.acalib.2015.06.007.

[9] Blanchet, K.; James, P. (2012). How to do (or not to do) a social network analysis in health systems research. Health Policy Plan Volume 27, 438-446. DOI :/10.1093/heapol/czr055.

[10] Borgatti, S.P.; Everett, M.G.; Freeman, L.C. (2012). Ucinet for Windows: Software for Social Network Analysis, 6th ed.; Analytic Technologies: Harvard, MA, USA.

[11] Mark, B. (2016). Social capital and collective identity in the local food movement, International Journal of Agricultural Sustainability, Volume 14:2, pp. 123-141. DOI: 10.1080/14735903.2015.1042189.

[12] Setatama, M \& Tricahyono, D." Implementasi Social Network Analysis pada Penyebaran Country Branding "Wonderful Indonesia"". Indonesian Journal on Computing (Indo-JC) Volume 2. pp. 91-104, November. 2017, doi: 10.21108/INDOJC.2017.2.2.183.

[13] Yusainy, C., Chawa, A \& Kholifah, . "Social Data Analytics sebagai Metode Alternatif dalam Riset Psikologi". Jurnal Buletin Psikologi Volume 25, pp. 67-75, November.
2017 ,

doi:

10.22146/buletinpsikologi.27751

[14] Jatain, A., and Ranjan, A. "A Review Study on Big Data Analysis Using R Studio". International Journal of Computer Science, Volume 6, pp. 8-17, 2017.

[15] Liu, B. " Sentiment Analysis: Mining Sentiments, Opinions, And Emotions". United Kingdom : Cambridge University Press, 2015.

[16] Yusainy, C., Chawa, A \& Kholifah, . "Social Data Analytics sebagai Metode Alternatif dalam Riset Psikologi". Jurnal Buletin Psikologi Volume 25, pp. 67-75, November. 2017 , doi: 10.22146/buletinpsikologi.27751.

[17] Pew Research. "Mapping Twitter Topic Networks: From Polarized Crowds to Community Clusters". Pewresearch Foundation. Available https://www.pewresearch.org/internet/2014/ 02/20/mapping-twitter-topic-networksfrom-polarized-crowds-to-communityclusters/

[18] Adalat, M, Niazi, M. and Vasilakos. A. "Variations in power of opinion leaders in online communication networks". Journal of Royal Society Open Science, Volume 5, 10, pp. 5-23, November. 2018, doi : https://doi.org/10.1098/rsos.180642

[19] Mansell, R., and Hwa, P. "The International Encyclopedia of Digital Communication and Society". Oxford, UK : WileyBlackwell, 2015, pp. 1027-1034.

[20] Christiansen." Four Stages of Social Movements.Journal of Research Starts". Norwegia : Ebsco Publishing, 2017. pp. 1-7.

[21] Porta, D. and Diani, M. " Introduction: The Field of Social Movement Studies". Oxford Handbooks Online, Volume 2, November. 2015, pp. 2-81. doi: 10.1093/oxfordhb/9780199678402.013.61

[22] Brunkers, F., Wischnewski M., Marbababie M., \& Meinert J. "The Role of Social Media during Social Movements - Observations 
from the \#metoo Debate on Twitter". United States : Conference Paper : Hawaii International Conference on System Sciences, 2020. Available: https://pdfs.semanticscholar.org/e7fa/cde6c 1472aa9c891a3c04e4c81de2c23fc2a.pdf.

[23] Polletta, F. \& Jasper, J. "Collective Identity in Social Movements". Journal of Annu. Rev. Sociol Volume 27, Pp. 283-305, February 2011, doi: 10.1146/annurev.soc.27.1.283.

[24] Wisnu, R. "Aktivisme dan Kesukarelawanan dalam Media Sosial". Jurnal Ilmu Sosial dan Ilmu Politik Volume 19, Nomor 1, Juli. 2015. Pp.40-52.

[25] Pond, P. \& Lewis, J. "Riots and Twitter: Connective Politics, Social Media And Framing Discourses In The Digital Public Sphere. Information". Journal of Communication \& Society Volume 22, Pp. 1-19, August. 2017, doi : 10.1080/1369118X.2017.1366539.

[26] Shawki N. "Understanding the Transnational Diffusion of Social Movements: An Analysis of the U.S. Solidarity Economy Network and Transition US". Journal of Humanity \& Society, Volume 37 (2): pp.131-158, April. 2013 doi:10.1177/0160597613481799.

[27] Smith, M., Shneiderman, B., Rainie, L. \& Himelboim, I. "Mapping Twitter Topic Networks: From Polarized Crowds to Community Clusters". Pewresearch Center. Retrieved From

https://www.pewresearch.org/internet/2014/ 02/20/mapping-twitter-topic-networksfrom-polarized-crowds-to-communityclusters/ 